\title{
Effects of airborne pollutants on mitochondrial DNA Methylation
}

\author{
Hyang-Min Byun ${ }^{1,6^{*}}$, Tommaso Panni ${ }^{1,2}$, Valeria Motta ${ }^{1,3}$, Lifang Hou ${ }^{4}$, Francesco Nordio ${ }^{1}$, Pietro Apostoli ${ }^{5}$,
} Pier Alberto Bertazzi ${ }^{3}$ and Andrea A Baccarelli ${ }^{1}$

\begin{abstract}
Background: Mitochondria have small mitochondrial DNA (mtDNA) molecules independent from the nuclear DNA, a separate epigenetic machinery that generates mtDNA methylation, and are primary sources of oxidative-stress generation in response to exogenous environments. However, no study has yet investigated whether mitochondrial DNA methylation is sensitive to pro-oxidant environmental exposures.

Methods: We sampled 40 male participants (20 high-, 20 low-exposure) from each of three studies on airborne pollutants, including investigations of steel workers exposed to metal-rich particulate matter (measured as $\mathrm{PM}_{1}$ ) in Brescia, Italy (Study 1); gas-station attendants exposed to air benzene in Milan, Italy (Study 2); and truck drivers exposed to traffic-derived Elemental Carbon (EC) in Beijing, China (Study 3). We have measured DNA methylation from buffy coats of the participants. We measured methylation by bisulfite-Pyrosequencing in three mtDNA regions, i.e., the transfer RNA phenylalanine (MT-TF), $12 S$ ribosomal RNA (MT-RNR1) gene and "D-loop" control region. All analyses were adjusted for age and smoking.
\end{abstract}

Results: In Study 1, participants with high metal-rich $\mathrm{PM}_{1}$ exposure showed higher MT-TF and MT-RNR1 methylation than low-exposed controls (difference $=1.41, P=0.002$ ); MT-TF and MT-RNR1 methylation was significantly associated with $\mathrm{PM}_{1}$ exposure (beta $=1.35, P=0.025$ ); and MT-RNR1 methylation was positively correlated with mtDNA copy number $(r=0.36 ; P=0.02)$. D-loop methylation was not associated with $\mathrm{PM}_{1}$ exposure. We found no effects on mtDNA methylation from air benzene (Study 2) and traffic-derived EC exposure (Study 3).

Conclusions: Mitochondrial MT-TF and MT-RNR1 DNA methylation was associated with metal-rich $\mathrm{PM}_{1}$ exposure and mtDNA copy number. Our results suggest that locus-specific mtDNA methylation is correlated to selected exposures and mtDNA damage. Larger studies are needed to validate our observations.

Keywords: Air pollutants, Mitochondria, DNA methylation

\section{Background}

Growing evidence from experimental models and human studies has shown that DNA methylation in the nuclear genome is susceptible to change in response to environmental exposures $[1,2]$. Epigenetic research on environmental exposures - such as airborne pollutants - that induce oxidative-stress in humans has consistently shown DNA methylation alterations in peripheral blood nuclear DNA

\footnotetext{
* Correspondence: hmbyun@hsph.harvard.edu

${ }^{1}$ Laboratory of Environmental Epigenetics, Exposure Epidemiology and Risk Program, Harvard School of Public Health, Boston, MA, USA

${ }^{6}$ Laboratory of Environmental Epigenetics, Exposure Epidemiology and Risk Program, Harvard School of Public Health, Room B12, 667 Huntington

Avenue, Boston, MA 02115, USA

Full list of author information is available at the end of the article
}

[1,3-6]. DNA methylation has thus been proposed to reflect environmentally-induced epigenomic reprogramming and risk of future disease [7-9].

Mitochondrial dysfunction has been identified as an etiological determinant of a variety of human diseases. The vast majority of mitochondrial proteins are encoded in the nucleus and synthesized in the cytoplasm, but are imported into the mitochondria [10]. Mitochondrial DNA (mtDNA) is a small independent circular genome of $16.5 \mathrm{~kb}$ in humans. MtDNA includes genes encoding for 13 proteins, 22 transfer RNAs (tRNAs), and 2 ribosomal RNAs (rRNAs), which are synthesized by a separate mitochondrial translation system [11]. Mitochondria lack protective histones and have a relatively inefficient DNA repair

\section{Biomed Central}

(c) 2013 Byun et al.; licensee BioMed Central Ltd. This is an Open Access article distributed under the terms of the Creative Commons Attribution License (http://creativecommons.org/licenses/by/2.0), which permits unrestricted use, distribution, and reproduction in any medium, provided the original work is properly cited. 
system [12]. Therefore mtDNA is particularly vulnerable to reactive oxygen species (ROS), which are established determinants of DNA methylation alterations [13]. Exposure to airborne pollutants has been linked with increased mitochondrial DNA copy number [14], a marker of mtDNA damage, and alterations in mitochondrial gene expression [15].

Although mtDNA methylation was described more than three decades ago [16,17], methylation in the mtDNA genome has been inconsistently and rarely studied, mostly due to long-standing controversies about its functionality. In fact, up until the recent discovery of the mtDNA methyltransferase enzyme 1 (mtDNMT1) [18], mtDNA methylation did not appear to be actively regulated in mitochondria, thus hampering any conclusion about potential functions. Shock et al. demonstrated the presence of mtDNMT1 activity and cytosine methylation in mtDNA, as well as that mtDNMT1 translocates to mitochondria following a mitochondrion-targeting signal upstream of translational start sites [18]. MtDNMT1 gene expression is controlled by oxidative stress [18], a primary mediator of air pollution effects. Alteration of mtDNMT1 expression directly affects the transcription of mtDNA genes [18], thus confirming that mitochondrial gene transcripts are controlled by mtDNA methylation.

Despite these recent breakthroughs and widespread emerging interest in mtDNA methylation, whether environmental exposures influence epigenetic mechanisms in mtDNA has not yet been explored, particularly in human investigations. In the present study, we examined whether mtDNA methylation in three specific mtDNA loci, i.e., the MT-TF, MT-RNR1 and displacement loop (D-loop) regions, differed in individuals with exposures to airborne pollutants. Mitochondrial tRNAs are essential for protein synthesis in mitochondria. Alteration in MT-TF is associated with several disease, such as neuromuscular disease [19], myoclonic epilepsy with ragged red fibers [20], mitochondrial myopathy [21], acute rhabdomyolysis [22], tubulointerstitial nephritis and stroke [23]. The MT-RNR1 gene encodes for a protein that facilitates the formation of RNA secondary structures, assembly of the mitochondrial ribosome, and mitochondrial translation [24]. The D-loop region that we examined contains promoters for mtDNA transcription and nearly the entire mitochondrial genome transcribes from the D-loop [25]. We sampled groups with high- and low-exposure from three independent studies on different types of airborne pollutants including steel workers and controls exposed to metal-rich particulate matter $\left(\mathrm{PM}_{1}\right)$ in Brescia, Italy (Study $1)$; gas-station attendants and controls exposed to trafficderived air benzene in Milan, Italy (Study 2); and truck drivers and controls exposed to traffic-derived Elemental Carbon (EC) (Study 3) in Beijing, China. We also examined the association of mtDNA methylation with mtDNA copy number to add evidence to the functional significance of mtDNA methylation.

\section{Results}

Participant's characteristics and exposure levels

Study 1 included workers from a steel-production plant in Brescia, Northern Italy, among whom we identified a high- and low-exposed group - each including 20 individuals - based on levels of exposure to metal-rich $\mathrm{PM}_{1}$. In the high-exposed steel workers, mean age was $42.5 \pm 7.7$ years, and 12 of them were ex/current smokers. In the controls, mean age was $37.6 \pm 2.8$ years, and 14 of them were ex/current smokers. The mean individual $\mathrm{PM}_{1}$ levels were $9.2 \pm 2.4 \mu \mathrm{g} / \mathrm{m}^{3}$ (range: $7.6-11.8 \mu \mathrm{g} / \mathrm{m}^{3}$ ) in high-exposed steel workers and $2.5 \pm 0.7 \mu \mathrm{g} / \mathrm{m}^{3}$ (range: $1.7-3.8 \mu \mathrm{g} / \mathrm{m}^{3}$ ) among controls (Table 1 ).

Study 2 included 20 gas-station attendants with exposure to airborne benzene and 20 office workers as a control group. The mean age was $39.9 \pm 11.2$ in gasstation attendants and $39.7 \pm 10.4$ in office workers. Seven gas-station attendants and 5 controls were ex/current smokers. The mean personal benzene levels were $78.6 \pm$ $42.5 \mu \mathrm{g} / \mathrm{m}^{3}$ (range: $31.2-180.1 \mu \mathrm{g} / \mathrm{m}^{3}$ ) in gas-station attendants and $7.0 \pm 5.5 \mu \mathrm{g} / \mathrm{m}^{3}$ (range: $4.2-23.0 \mu \mathrm{g} / \mathrm{m}^{3}$ ) in controls (Table 1).

Study 3 included 20 truck drivers with exposure to traffic-derived air particles, measured as EC levels and 20 office workers as a control group, all living and working in Beijing, China. Mean age was $35.2 \pm 5.1$ years in truck drivers and $33.4 \pm 5.9$ in controls. Eight truck drivers and 6 controls were ex/current smokers. Mean individual EC exposure was $21.3 \pm 4.7 \mu \mathrm{g} / \mathrm{m}^{3}$ (range $16.6-35.6 \mu \mathrm{g} / \mathrm{m}^{3}$ ) in truck drivers and $13.4 \pm 2.1 \mu \mathrm{g} / \mathrm{m}^{3}$ (range: $7.8-16.1 \mu \mathrm{g} / \mathrm{m}^{3}$ ) in controls (Table 1).

All participants were healthy and did not report any chronic diseases at the time of recruitment.

\section{Levels of mtDNA methylation by group of exposure}

To determine the effect of environmental exposures on mtDNA methylation, we first contrasted high-exposure groups to controls in analysis adjusted for age and smoking (Table 2). In Study 1, MT-TF and MT-RNR1 gene methylation was significantly higher in steel workers $(6.47 \% \pm 0.29)$ with high-exposure to $\mathrm{PM}_{1}$ exposure compared to controls $(5.06 \% \pm 0.30 ; P=0.002)$. The distribution of MT-TF and MT-RNR1 gene methylation among high-exposed steel workers and controls is shown in Figure 1. MtDNA methylation of the D-loop region was $2.16 \% \pm 0.17$ in high-exposed steel workers and $2.18 \% \pm$ 0.17 in controls $(P=0.93)$ (Table 2). In Study 2 and Study 3 , gas-station attendants and truck drivers did not show differences in DNA methylation compared to their respective control groups (Table 2). 
Table 1 Characteristics and exposure-levels of the study participants

\begin{tabular}{|c|c|c|c|c|}
\hline Study & & Characteristics & High exposure & Low exposure \\
\hline \multirow{5}{*}{$\begin{array}{l}\text { Study } 1 \text { Exposure to metal-rich } \\
\text { particulate matter (PM) }\end{array}$} & & & High-exposed steel workers $(n=20)$ & Controls $(n=20)$ \\
\hline & Participants & Age $[$ Years], mean \pm SD & $42.5 \pm 7.7$ & $37.6 \pm 2.8$ \\
\hline & & Ex/current smokers, n (\%) & $12(60)$ & $14(70)$ \\
\hline & Exposure $\left(\mathrm{PM}_{1}, \mu \mathrm{g} / \mathrm{m}^{3}\right)$ & Mean \pm SD & $9.2 \pm 2.4$ & $2.5 \pm 0.7$ \\
\hline & & Range & {$[7.6 ; 11.8]$} & {$[1.7 ; 3.8]$} \\
\hline \multirow[t]{5}{*}{ Study 2 Exposure to air benzene } & & & Gas-station attendants $(\mathrm{n}=20)$ & Controls $(n=20)$ \\
\hline & Participants & Age [Years], mean $\pm S D$ & $39.9 \pm 11.2$ & $39.7 \pm 10.4$ \\
\hline & & Ex/current smokers, n (\%) & $7(35)$ & $5(25)$ \\
\hline & Exposure (Benzene, $\mu \mathrm{g} / \mathrm{m}^{3}$ ) & Mean \pm SD & $78.6 \pm 42.5$ & $7.0 \pm 5.5$ \\
\hline & & Range & {$[31.2 ; 180.1]$} & {$[4.2 ; 23.0]$} \\
\hline \multirow{5}{*}{$\begin{array}{c}\text { Study } 3 \text { Exposure to traffic-derived } \\
\text { elemental carbon }\end{array}$} & & & Truck drivers $(n=20)$ & Controls $(n=20)$ \\
\hline & Participants & Age $[$ Years], mean \pm SD & $35.2 \pm 5.1$ & $33.4 \pm 5.9$ \\
\hline & & Ex/current smokers, n (\%) & $8(40)$ & $6(30)$ \\
\hline & Exposure & Mean \pm SD & $21.3 \pm 4.7$ & $13.4 \pm 2.1$ \\
\hline & tal ca & Range & {$[16.6 ; 35.6]$} & {$[7.8 ; 16.1]$} \\
\hline
\end{tabular}

SD: standard deviation.

Only male participants were selected in the present study.

Association of mtDNA methylation with exposure levels

We used multiple linear regression models adjusted for age and smoking to evaluate the association of mtDNA methylation with continuous levels of exposure to airborne pollutants in the three studies (Table 3). We calculated $\beta$ coefficients to estimate the difference in mtDNA methylation between the 90th and 10th percentile of the distribution of exposure levels. In Study 1, $\mathrm{PM}_{1}$ levels were positively associated with MT-TF and MT-RNR1 gene methylation $(\beta=1.35, \mathrm{SD}=0.33$, and $P=0.025$; Table 3$)$. Mitochondrial D-loop region methylation was not associated with $\mathrm{PM}_{1}(\beta=-0.02, \mathrm{SD}=0.17 ; P=0.96)$. We have also examined the association of mtDNA methylation with $\mathrm{PM}_{2.5}$, however it did not show a significant association (data not shown). In Study 2, air benzene levels were associated with neither $M T-T F$ and $M T-R N R 1$ gene methylation $(\beta=-0.37, \mathrm{SD}=0.08 ; P=0.18)$ nor $\mathrm{D}$-loop region methylation $(\beta=-0.03, \mathrm{SD}=0.08 ; P=0.91)$. In Study 3, EC exposure was associated with neither $M T-T F$ and MT-RNR1 gene methylation $(\beta=-0.18, \mathrm{SD}=0.51$; $P=0.64)$ nor mitochondrial $D$-loop region methylation $(\beta=0.56, \mathrm{SD}=0.85 ; P=0.37)$.

\section{Sensitivity analyses}

In sensitivity analyses, we repeated all statistical analyses after log-transforming the DNA methylation variables and found no major differences in the results (data not shown). We also conducted sensitivity analyses to exclude influences from potential differences in the proportion of blood leukocyte subtypes on the significant results

Table 2 Mitochondrial DNA methylation level (\%) by exposure groups of airborne pollutants

\begin{tabular}{|c|c|c|c|}
\hline \multicolumn{4}{|c|}{ Study 1} \\
\hline & High-exposed steel workers $(n=20)$ & Controls $(n=20)$ & $\overline{p \text {-value }}$ \\
\hline MT-TF \& MT-RNR1 & $6.47 \% \pm 0.29$ & $5.06 \% \pm 0.30$ & 0.002 \\
\hline D-loop & $2.16 \% \pm 0.17$ & $2.18 \% \pm 0.17$ & 0.93 \\
\hline \multicolumn{4}{|c|}{ Study 2} \\
\hline & Gas-station attendants $(n=20)$ & Controls $(n=20)$ & p-value \\
\hline$M T-T F \& M T-R N R 1$ & $5.52 \% \pm 0.22$ & $5.89 \% \pm 0.23$ & 0.22 \\
\hline D-loop & $1.68 \% \pm 0.16$ & $1.55 \% \pm 0.16$ & 0.53 \\
\hline \multicolumn{4}{|c|}{ Study 3} \\
\hline & Truck drivers $(n=20)$ & Controls $(n=20)$ & $\mathrm{p}$-value \\
\hline$M T-T F \& M T-R N R 1$ & $5.37 \% \pm 0.22$ & $5.41 \% \pm 0.22$ & 0.88 \\
\hline D-loop & $2.46 \% \pm 0.54$ & $2.38 \% \pm 0.53$ & 0.82 \\
\hline
\end{tabular}

Data are presented as means \pm standard deviations (SDs). Analysis adjusted for age and smoking status. 


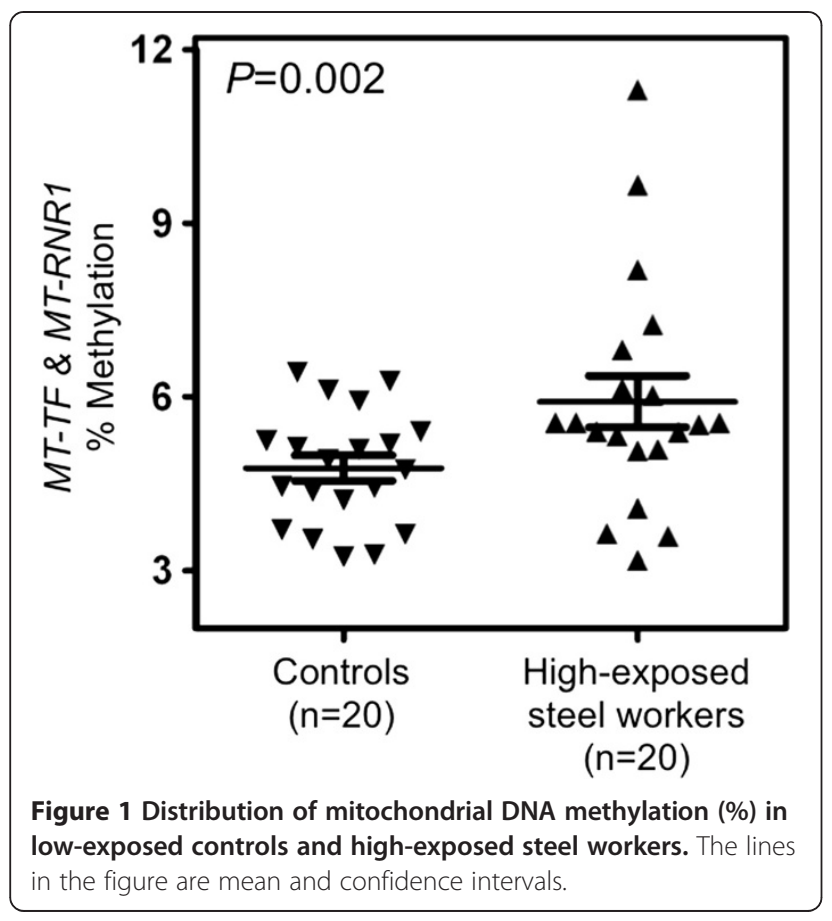

observed in Study 1; multiple regression models that included percent granulocytes as independent variables in addition to age and smoking - showed only negligible differences in the regression estimates for Study 1 and no changes in statistical significance (data not shown).

\section{Mitochondrial gene methylation and relative mitochondrial DNA copy number}

To explore the functional significance of the association of MT-TF and MT-RNR1 gene methylation with exposure to metal-rich $\mathrm{PM}_{1}$ in Study 1, we evaluated the correlation of mitochondrial MT-TF and MT-RNR1 methylation with mtDNA copy number, a measure of damaged dysfunctional mitochondria. We obtained the mtDNA copy number by calculating the ratio between the estimated numbers of a mitochondrial gene and nuclear single copy gene, as previously reported for the same study [14]. As shown in Figure 2, individuals with higher MTTF and MT-RNR1 gene methylation exhibited higher mtDNA copy number $(\mathrm{r}=0.36 ; P=0.02)$.

\section{Discussion}

In the present work, we measured DNA methylation at two mtDNA regions in individuals with exposures to three different types of air pollutants. We report, for the first time, associations of mtDNA methylation with exposure to air pollutants. Specifically, steel workers with high exposure to metal-rich PM exhibited higher levels of mitochondrial MT-TF and MT-RNR1 gene methylation. Further, higher MT-RNR1 gene methylation was significantly correlated with higher mtDNA copy number.

MtDNA methylation was first observed in 1984 in mice and reported to occur at very low level $(<5 \%)$ using global measures of mtDNA methylation [26]. In the present work, we used a newly-developed quantitative and sensitive DNA methylation assays of mitochondrial MT-RNR1 and D-loop methylation based on bisulfite-Pyrosequencing. Using this approach, we identified a subtle but significant difference in mtDNA methylation in steel workers exposed to metal-rich $\mathrm{PM}_{1}$ compared to controls. To the best of our knowledge, this finding represents the first report of a potential effect from environmental pollutants on mtDNA methylation in humans.

Mitochondria supply cellular energy by generating ATP through the respiration and oxidative phosphorylation (OXPHOS) system. The OXPHOS system is the primary intracellular source of ROS and free radicals under normal physiological and pathological conditions. Mitochondrial dysfunction may occur upon exposure to oxidative stress, and air pollutants are a well-established environmental source of cellular oxidative stress [27]. Microarray analyses have suggested that almost a quarter of the cellular responses to oxidative stress are mediated

Table 3 Associations of mitochondrial DNA methylation with exposure levels of airborne pollutants

\begin{tabular}{|c|c|c|c|}
\hline Marker & $\beta *^{\dagger}$ & SD* & p-value* \\
\hline & \multicolumn{3}{|c|}{ Study 1 - Association with metal-rich particulate matter $\left(\mathrm{PM}_{1}\right)$} \\
\hline$M T-T F \& M T-R N R 1$ & 1.35 & 0.33 & 0.025 \\
\hline \multirow[t]{2}{*}{ D-loop } & -0.02 & 0.17 & 0.96 \\
\hline & \multicolumn{3}{|c|}{ Study 2 - Association with airborne benzene } \\
\hline$M T-T F \& M T-R N R 1$ & -0.37 & 0.08 & 0.18 \\
\hline \multirow[t]{2}{*}{ D-loop } & -0.03 & 0.08 & 0.91 \\
\hline & \multicolumn{3}{|c|}{ Study 3 - Association with traffic-derived elemental carbon } \\
\hline MT-TF \& MT-RNR1 & -0.18 & 0.51 & 0.64 \\
\hline D-loop & 0.56 & 0.85 & 0.37 \\
\hline
\end{tabular}

*Adjusted for age and smoking status. Exposure variables were log-transformed to improve model fit.

† Regression coefficient estimating the difference in mitochondrial DNA methylation (\%) associated with an increase in exposure levels from the 90th to the $10^{\text {th }}$ percentile. 


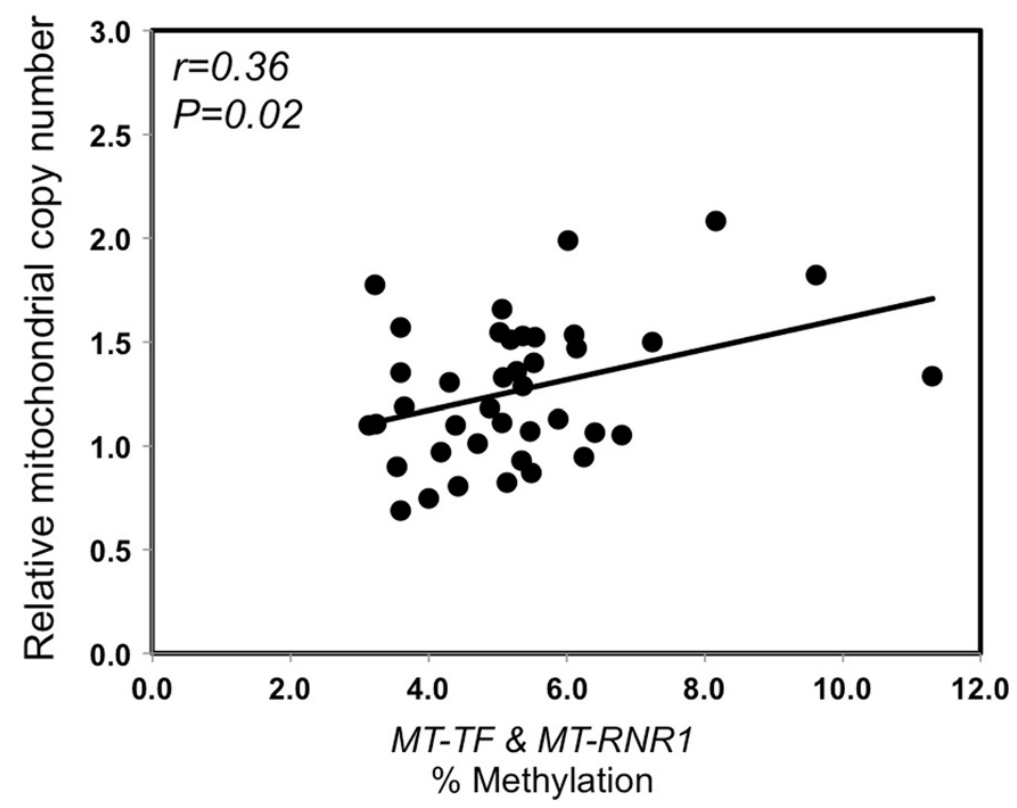

Figure 2 Correlation between relative mitochondria copy number and mitochondrial gene MT-TF and MT-RNR1 methylation.

through mitochondrial dysfunction [28]. Van Houten et al. demonstrated that mtDNA accumulates 3-10 fold more damage than nuclear DNA after an oxidative-stress challenge [29]. PM is a major toxic component of air pollution that has been consistently associated in epidemiological investigations with increased incidence and mortality from respiratory disease [30], cardiovascular disease [14], and lung cancer [31]. We showed that mtDNA methylation in the MT-TF and MT-RNR1 gene was specifically associated with metal-rich $\mathrm{PM}_{1}$, whereas no association was found with airborne benzene or elemental carbon. Exposures pertaining to metal workers, who live in an environment with high oxidative potential, have been previously linked with mtDNA damage and mitochondrial dysfunction [32]. Taken together, these findings suggest that the chemical composition, source, and type of pollutant are critical to determine effects on mitochondrial DNA methylation. Future studies are warranted to evaluate the relative mitochondrial toxicity of metal-rich particles in larger prospective studies.

To explore the functional significance of the difference in MT-TF and MT-RNR1 gene methylation associated with higher exposure to metal-rich PM in Study 1, we also examined the relationship between mitochondrial MT-TF and MT-RNR1 methylation and mtDNA copy number and found a positive correlation between the two markers. Hobbie et al. have reported that a local conformational change in the $12 \mathrm{~S}$ rRNA encoded by MTRNR1 sequence affects the efficiency and accuracy of codon-anticodon interactions [33]. The stem-loop structure of the $12 \mathrm{~S}$ rRNA encoded by MT-RNR1 is critical for normal function and integrity of the mitochondrial ribosome, and structural changes of $12 \mathrm{~S}$ rRNA lead to decreased steady-state levels of $12 \mathrm{~S}$ rRNA, instability of the small subunit of the ribosome, and abolished mitochondrial translation [24]. DNA methylation in the MTRNR1 gene may cause malfunction of mitochondrial ribosomes and abolished translation of mtDNA-encoded RNAs into proteins. Alternatively, increased mtDNA copy number in the presence of increased MT-TF and MTRNR1 gene methylation could simply represent a compensatory mechanism directed to maintain normal cellular function and cope with the increased respiratory demand required for ROS clearance [34].

We recognize a number of limitations in the present work. We measured mtDNA methylation markers in small samples of only 40 participants from each of the three studies. We cannot exclude that type II error due to limited statistical power might have led to the lack of associations with benzene exposure in Study 2 and EC in Study 3, as well as to the null findings for the mitochondrial D-loop region methylation data in Study 1. Our analysis of mtDNA methylation was limited to two circumscribed regions of the mitochondrial genome. However, we selected two regions with potential functional impacts, including a promoter region and a key ribosomal RNA sequence. Methods for extensive sequencing of the mitochondrial genome have not yet been developed and methylation assays for other mtDNA sequences are not readily available. Future work is warranted to determine whether DNA methylation in other regions on the mtDNA is specifically sensitive to air pollutants. Finally, although recent experimental data demonstrate that mtDNA methylation regulates gene expression, we did not measure RNA 
expression in our data due to the lack of suitable RNA samples for expression analysis. Therefore, we cannot determine the direct functional significance on RNA expression of the small differences in mtDNA methylation that we observed in the present work. It would also be interested to examine the association between nuclear genes, and particularly mtDNMT1 expression, with mtDNA methylation.

In summary, in the present work we found a moderate difference in mtDNA methylation of the MT-TF and MT-RNR1 gene associated with exposure to metal rich PM. We did not find any difference in mtDNA methylation related to benzene and traffic-related EC level. Our data may serve as a preliminary conceptual model for larger future investigations of mtDNA methylation in human studies.

\section{Methods \\ Study population}

We sampled participants from three existing studies previously described in Dioni et al. [35] (Study 1); Bollati et al. [3] (Study 2); and Baccarelli et al. [36] (Study 3). From each of the three studies, we selected two groups of 20 high-exposed individuals and 20 low-exposed controls. In consideration of the predominance of males in the three studies and to limit potential confounding from gender, we only sampled male participants. In brief, from Study 1 we selected 20 individuals with high exposure to metalrich particles (Particulate Matter with aerodynamic diameter $\left.>1 \mu \mathrm{m}\left[\mathrm{PM}_{1}\right] \geq 7.6 \mu \mathrm{g} / \mathrm{m}^{3}\right)$ and 20 individuals with low exposure $\left(\mathrm{PM}_{1} \leq 3.8 \mu \mathrm{g} / \mathrm{m}^{3}\right)$ among workers in a steel production plant in Brescia, Italy. Personal $\mathrm{PM}_{1}$ levels were estimated using work-area measurements obtained through a GRIMM 1100 light-scattering dust analyzer (Grimm Technologies, Inc. Douglasville, GA, USA). From Study 2, we sampled 20 gas-station attendants with comparatively higher exposure to airborne benzene (personal airborne benzene $\geq 31.2 \mu \mathrm{g} / \mathrm{m}^{3}$ ) and 20 office workers with lower exposure (personal airborne benzene $\leq 23.0 \mu \mathrm{g} / \mathrm{m}^{3}$ ) in Milan, Italy. In all Study 2 participants, personal benzene exposure was determined by a passive sampler containing Chromosorb 106. From Study 3 , we sampled 20 truck drivers in Beijing, China with high exposure to Elemental Carbon $\left(\mathrm{EC} \geq 16.6 \mu \mathrm{g} / \mathrm{m}^{3}\right)$, taken as a tracer of traffic particles. Age-matched controls were 20 office workers in Beijing, China with individual EC levels $\leq 16.1 \mu \mathrm{g} / \mathrm{m}^{3}$. In Study 3, we measured personal EC levels using active small-sized gravimetric samplers worn by the study participants during the eight hours on the day of the work, and for two consecutive days. We used standardized procedures for all studies to collect and store peripheral blood and extract DNA from buffy coat $[3,35,36]$.

\section{DNA methylation analyses}

We performed DNA methylation analysis with highly quantitative bisulfite-PCR pyrosequencing. Genomic DNA was treated with the EZ DNA methylation Gold kit (Zymo Research, Orange, CA, USA) according to the manufacturer's instructions. Final elution volume was $40 \mu \mathrm{l}$ with M-elution buffer. We designed the assay for the 'MT-TF and MT-RNR1' and mitochondrial 'D-loop' regions (primer sequences are shown in Additional file 1: Table S1). The 'MT-TF and MT-RNR1' assay interrogated two CpGs from MT-TF and MT-RNR1. The distance between the two CpGs was 83 base pairs, thus we took an average of two CpGs for MT-TF and MT-RNR1 gene methylation. The analysis by each gene is shown in Additional file 1: Table S2. We have measured 3 CpGs from D-loop region and took an average for the analysis. In order to exclude contamination from nuclear DNA in PCR amplification, we designed primer sequences unique for mtDNA sequences. Primer sequence is based on GenBank accession number J01415.2 which is shown in the L-strand of mitochondrial complete genome. A $30 \mu \mathrm{l}$ of PCR was carried out using $15 \mu \mathrm{l}$ of GoTaq Green Master mix (Promega), 10 pmol forward and $10 \mathrm{pmol}$ reverse primers, $50 \mathrm{ng}$ of bisulfite-treated DNA, and water to reach $30 \mu \mathrm{l}$ final volume. PCR products were purified and sequenced by pyrosequencing as previously described using $0.3 \mu \mathrm{m}$ sequencing primer [3]. Information for PCR primer is shown in Additional file 1. To monitor the intra- and inter- plate variation, we added universal genomic DNA (random genomic DNA) to each plate. We designed control oligo for 100\% DNA methylation (PSQ-C oligo: 5' ${ }^{\prime}$ TTGCGATACGACGGGAACAAAC GTTGAATTC-3') and 0\% DNA methylation (PSQ-T oligo: 5'-TTGCGATACAACGGGAACAAACGTTGAATTC-3'). The sequencing primer for control oligo is $5^{\prime}$-AACGTTT GTTCCCGT-3'. We mixed PSQ-C oligo (or PSQ-T oligo) with sequencing oligo in PyroMark Annealing Buffer (QIAGEN Inc., Valencia, CA) and performed Pyrosequencing with sequencing entry C/TGTAT [37]. The methylation level is expressed using percent 5methylcytosine $(5 \mathrm{mC})$. The correlation coefficient of the interplate variation was less than 1 , which is considered low-variance. For example, the correlation coefficient of the D-loop assay in Study 1 was 0.56 .

\section{Measurement of mtDNA copy number}

Relative mtDNA copy number was measured by a quantitative real time polymerase chain reaction (Q-PCR) assay that measures the ratio of mitochondrial (Mt) copy number to single copy gene (S) copy number in experimental samples relative to a reference. The method is based on quantification of $\mathrm{Mt}$ and $\mathrm{S}$ quantities expressed as Cts derived from a standard curve obtained from serial dilutions of a reference DNA. A human beta-globin 
gene was used as reference single copy gene. The PCR primer and conditions are described in Hou L et al. [14]. Each run was completed by melting curve analysis to confirm the amplification specificity and absence of primer dimers. All samples were run in triplicates. For quality control purposes, 10 blind duplicate samples were interspersed among the test samples. The coefficient of variation for the $\mathrm{Mt} / \mathrm{S}$ ratio in duplicate samples was $3.2 \%$.

\section{Statistical analysis}

We used standard descriptive statistics to present the study participants' characteristics. Because DNA methylation results were obtained from two replicates that generated values for two or three CpG positions for MT-TF and MT-RNR1 or D-loop, respectively, we used mixed-effects regression models [7] to evaluate the average associations of each mtDNA methylation marker with exposure group (high vs. low) or exposure levels (continuous variables, log-transformed to achieve higher estimate precision), by adapting the methods described by Boeke et al. [38]. We checked regression assumptions by performing diagnostic tests for each model, including the Shapiro-Wilk test for normality of residuals and White test for homogeneity of variance of residuals. All models were adjusted for age and smoking. A two-sided $P<0.05$ was considered statistically significant. All statistical analyses were performed in SAS (version 9.2; SAS Institute Inc., Cary, NC, USA).

\section{Additional file}

Additional file 1: Table S1. Bisulfite-Pyrosequencing primer sequence information. Table S2. Associations of mitochondrial DNA methylation with exposure levels of airborne pollutants.

\section{Competing interests}

The authors declare that they have no competing interests.

\section{Authors' contributions}

$H M B$ and $A A B$ designed the experiment. TP and FN analyzed the data. HMB and $V M$ performed the experiments. $L F, P A, P A B$, and $A A B$ contributed participant's materials. $H M B$ and $A A B$ wrote the manuscript and $A A B$ oversaw the research. All authors have read and approved the final manuscript.

\section{Funding}

This work was supported by funding from the National Institute of Environmental Health Sciences (ES000002; R01ES020268; R21ES020010; and R21ES019773).

\footnotetext{
Author details

'Laboratory of Environmental Epigenetics, Exposure Epidemiology and Risk Program, Harvard School of Public Health, Boston, MA, USA. ${ }^{2}$ Department of Statistics, University of Milano-Bicocca, Milan, Italy. ${ }^{3}$ Department of Environmental and Occupational Health, Università degli Studi di Milano and IRCCS Ca' Granda Maggiore Policlinico Hospital, Milan, Italy. ${ }^{4}$ Department of Preventive Medicine, Feinberg School of Medicine, Northwestern University, 680 N. Lakeshore Drive, Chicago 60611, USA. ${ }^{5}$ Department of Experimental and Applied Medicine, Occupational Medicine and Industrial Hygiene, University of Brescia, Brescia, Italy. 'aboratory of Environmental Epigenetics, Exposure Epidemiology and Risk Program, Harvard School of Public Health, Room B12, 667 Huntington Avenue, Boston, MA 02115, USA.
}

Received: 31 August 2012 Accepted: 1 May 2013

Published: 8 May 2013

\section{References}

1. Baccarelli A, Wright RO, Bollati V, Tarantini L, Litonjua AA, Suh HH, Zanobetti A, Sparrow D, Vokonas PS, Schwartz J: Rapid DNA methylation changes after exposure to traffic particles. Am J Respir Crit Care Med 2009, 179:572-578.

2. Zama AM, Uzumcu M: Targeted genome-wide methylation and gene expression analyses reveal signaling pathways involved in ovarian dysfunction after developmental EDC exposure in rats. Biol Reprod 2013, 88:52.

3. Bollati V, Baccarelli A, Hou L, Bonzini M, Fustinoni S, Cavallo D, Byun HM, Jiang J, Marinelli B, Pesatori AC, et al: Changes in DNA methylation patterns in subjects exposed to low-dose benzene. Cancer Res 2007, 67:876-880.

4. Pavanello S, Bollati V, Pesatori AC, Kapka L, Bolognesi C, Bertazzi PA, Baccarelli A: Global and gene-specific promoter methylation changes are related to anti-B[a]PDE-DNA adduct levels and influence micronuclei levels in polycyclic aromatic hydrocarbon-exposed individuals. Int J Cancer 2009, 125:1692-1697.

5. Madrigano J, Baccarelli A, Mittleman MA, Wright RO, Sparrow D, Vokonas PS, Tarantini L, Schwartz J: Prolonged exposure to particulate pollution, genes associated with glutathione pathways, and DNA methylation in a cohort of older men. Environ Health Perspect 2011, 119:977-982.

6. Tarantini L, Bonzini M, Apostoli P, Pegoraro V, Bollati V, Marinelli B, Cantone L, Rizzo G, Hou L, Schwartz J, et al: Effects of particulate matter on genomic DNA methylation content and iNOS promoter methylation. Environ Health Perspect 2009, 117:217-222.

7. Hou L, Zhang X, Tarantini L, Nordio F, Bonzini M, Angelici L, Marinelli B, Rizzo G, Cantone L, Apostoli P, et al: Ambient PM exposure and DNA methylation in tumor suppressor genes: a cross-sectional study. Part Fibre Toxicol 2011, 8:25.

8. Baccarelli A, Wright R, Bollati V, Litonjua A, Zanobetti A, Tarantini L, Sparrow D, Vokonas P, Schwartz J: Ischemic heart disease and stroke in relation to blood DNA methylation. Epidemiology 2010, 21:819-828.

9. Pearce MS, McConnell JC, Potter C, Barrett LM, Parker L, Mathers JC, Relton CL: Global LINE-1 DNA methylation is associated with blood glycaemic and lipid profiles. Int J Epidemiol 2012, 41:210-217.

10. Stojanovski D, Johnston AJ, Streimann I, Hoogenraad NJ, Ryan MT: Import of nuclear-encoded proteins into mitochondria. Exp Physiol 2003, 88:57-64.

11. Anderson S, Bankier AT, Barrell BG, de Bruijn MH, Coulson AR, Drouin J, Eperon IC, Nierlich DP, Roe BA, Sanger F, et al: Sequence and organization of the human mitochondrial genome. Nature 1981, 290:457-465.

12. Wallace DC: Diseases of the mitochondrial DNA. Annu Rev Biochem 1992, 61:1175-1212.

13. Valinluck V, Tsai HH, Rogstad DK, Burdzy A, Bird A, Sowers LC: Oxidative damage to methyl-CpG sequences inhibits the binding of the methyl-CpG binding domain (MBD) of methyl-CpG binding protein 2 (MeCP2). Nucleic Acids Res 2004, 32:4100-4108.

14. Hou L, Zhu ZZ, Zhang X, Nordio F, Bonzini M, Schwartz J, Hoxha M, Dioni L, Marinelli B, Pegoraro $V$, et al: Airborne particulate matter and mitochondrial damage: a cross-sectional study. Environ Health 2010, 9:48.

15. Xu Z, Xu X, Zhong M, Hotchkiss IP, Lewandowski RP, Wagner JG, Bramble $L A$, Yang $Y$, Wang $A$, Harkema JR, et al: Ambient particulate air pollution induces oxidative stress and alterations of mitochondria and gene expression in brown and white adipose tissues. Part Fibre Toxicol 2011, 8:20.

16. Dawid IB: 5-methylcytidylic acid: absence from mitochondrial DNA of frogs and HeLa cells. Science 1974, 184:80-81.

17. Levi R, Pappano AJ: Modification of the effects of histamine and norepinephrine on the sinoatrial node pacemaker by potassium and calcium. J Pharmacol Exp Ther 1978, 204:625-633.

18. Shock LS, Thakkar PV, Peterson E, Moran RG, Taylor SM: DNA methyltransferase 1, cytosine methylation, and cytosine hydroxymethylation in mammalian mitochondria. Proc Natl Acad Sci USA 2011, 108:3630-3635.

19. Deschauer M, Swalwell H, Strauss M, Zierz S, Taylor RW: Novel mitochondrial transfer RNA(Phe) gene mutation associated with late-onset neuromuscular disease. Arch Neurol 2006, 63:902-905.

20. Mancuso M, Filosto M, Mootha VK, Rocchi A, Pistolesi S, Murri L, DiMauro S, Siciliano G: A novel mitochondrial tRNAPhe mutation causes MERRF syndrome. Neurology 2004, 62:2119-2121. 
21. Moslemi AR, Lindberg C, Toft J, Holme E, Kollberg G, Oldfors A: A novel mutation in the mitochondrial tRNA(Phe) gene associated with mitochondrial myopathy. Neuromuscul Disord 2004, 14:46-50.

22. Chinnery PF, Johnson MA, Taylor RW, Lightowlers RN, Turnbull DM: A novel mitochondrial tRNA phenylalanine mutation presenting with acute rhabdomyolysis. Ann Neurol 1997, 41:408-410.

23. Tzen CY, Tsai JD, Wu TY, Chen BF, Chen ML, Lin SP, Chen SC: Tubulointerstitial nephritis associated with a novel mitochondrial point mutation. Kidney Int 2001, 59:846-854.

24. Metodiev MD, Lesko N, Park CB, Camara Y, Shi Y, Wibom R, Hultenby K, Gustafsson CM, Larsson NG: Methylation of $12 \mathrm{~S}$ rRNA is necessary for in vivo stability of the small subunit of the mammalian mitochondrial ribosome. Cell Metab 2009, 9:386-397.

25. Aloni Y, Attardi G: Expression of the mitochondrial genome in HeLa cells. II. Evidence for complete transcription of mitochondrial DNA. J Mol Biol 1971, 55:251-267.

26. Pollack Y, Kasir J, Shemer R, Metzger S, Szyf M: Methylation pattern of mouse mitochondrial DNA. Nucleic Acids Res 1984, 12:4811-4824.

27. Lodovici M, Bigagli E: Oxidative stress and air pollution exposure. J Toxicol 2011, 2011:487074.

28. Shibanuma M, Inoue A, Ushida K, Uchida T, Ishikawa F, Mori K, Nose K: Importance of mitochondrial dysfunction in oxidative stress response: A comparative study of gene expression profiles. Free Radic Res 2011, 45:672-680.

29. Van Houten B, Woshner V, Santos JH: Role of mitochondrial DNA in toxic responses to oxidative stress. DNA Repair (Amst) 2006, 5:145-152.

30. Kamdar O, Le W, Zhang J, Ghio AJ, Rosen GD, Upadhyay D: Air pollution induces enhanced mitochondrial oxidative stress in cystic fibrosis airway epithelium. FEBS Lett 2008, 582:3601-3606.

31. Brook RD, Franklin B, Cascio W, Hong Y, Howard G, Lipsett M, Luepker R, Mittleman M, Samet J, Smith SC Jr, Tager I: Air pollution and cardiovascular disease: a statement for healthcare professionals from the Expert Panel on Population and Prevention Science of the American Heart Association. Circulation 2004, 109:2655-2671.

32. Shukla A, Jung M, Stern M, Fukagawa NK, Taatjes DJ, Sawyer D, Van Houten B, Mossman BT: Asbestos induces mitochondrial DNA damage and dysfunction linked to the development of apoptosis. Am J Physiol Lung Cell Mol Physiol 2003, 285:L1018-L1025.

33. Hobbie SN, Bruell CM, Akshay S, Kalapala SK, Shcherbakov D, Bottger EC: Mitochondrial deafness alleles confer misreading of the genetic code. Proc Natl Acad Sci USA 2008, 105:3244-3249.

34. Sitarz KS, Yu-Wai-Man P, Pyle A, Stewart JD, Rautenstrauss B, Seeman P, Reilly MM, Horvath R, Chinnery PF: MFN2 mutations cause compensatory mitochondrial DNA proliferation. Brain 2012, 135(Pt 8):e219. 1-3.

35. Dioni L, Hoxha M, Nordio F, Bonzini M, Tarantini L, Albetti B, Savarese A, Schwartz J, Bertazzi PA, Apostoli P, et al: Effects of short-term exposure to inhalable particulate matter on telomere length, telomerase expression, and telomerase methylation in steel workers. Environ Health Perspect 2011, 119:622-627.

36. Baccarelli A, Barretta F, Dou C, Zhang X, McCracken JP, Diaz A, Bertazzi PA, Schwartz J, Wang S, Hou L: Effects of particulate air pollution on blood pressure in a highly exposed population in Beijing, China: a repeatedmeasure study. Environ Health 2011, 10:108.

37. Byun HM, Heo K, Mitchell K, Yang AS: Mono-allelic retrotransposon insertion addresses epigenetic transcriptional repression in human genome. J Biomed Sci 2012, 19:13.

38. Boeke CE, Baccarelli A, Kleinman KP, Burris HH, Litonjua AA, Rifas-Shiman SL, Tarantini L, Gillman M: Gestational intake of methyl donors and global LINE-1 DNA methylation in maternal and cord blood: prospective results from a folate-replete population. Epigenetics 2012, 7:253-260.

doi:10.1186/1743-8977-10-18

Cite this article as: Byun et al:: Effects of airborne pollutants on mitochondrial DNA Methylation. Particle and Fibre Toxicology 2013 10:18.

\section{Submit your next manuscript to BioMed Central and take full advantage of:}

- Convenient online submission

- Thorough peer review

- No space constraints or color figure charges

- Immediate publication on acceptance

- Inclusion in PubMed, CAS, Scopus and Google Scholar

- Research which is freely available for redistribution

Submit your manuscript at www.biomedcentral.com/submit 